\title{
RESTRICTION ENDONUCLEASE ANALYSIS OF CAMPYLOBACTER STRAINS WITH PARTICULAR REFERENCE TO CAMPYLOBACTER FETUS SS. FETUS
}

\author{
D. M. Collins and D. E. Ross \\ Animal Health Reference Laboratory, Wallaceville Animal Research Centre, \\ Upper Hutt, New Zealand
}

\begin{abstract}
SUMmARY. Forty-three strains of Campylobacter fetus ss. fetus isolated from sheep abortions in New Zealand, and reference strains of $C$. fetus ss. fetus (four), C. fetus ss. venerealis (two), $C$. jejuni (one) and $C$. coli (one) were examined by restriction endonuclease analysis with the enzymes BstE II and Xho I. DNA fragment patterns of C. fetus, $C$. jejuni and $C$. coli differed strikingly from each other, but there were many similarities in the patterns obtained for all strains of $C$. fetus ss. fetus (47) and C. fetus ss. venerealis (three). The 43 local strains of $C$. fetus ss. fetus were clearly divided into four types. Two of these types produced patterns nearly identical with those of overseas reference strains.
\end{abstract}

\section{INTRODUCTION}

The genus Campylobacter has undergone several major changes of classification in the last 20 years but is at present strongly influenced by the following "approved names" (Skerman, McGowan and Sneath, 1980): C. fetus, with its subspecies fetus and venerealis (the subspecies intestinalis and fetus, respectively, of Smibert, 1978); C. jejuni and $C$. coli, which together represent Smibert's (1978) C. fetus subspecies jejuni; and $C$. sputorum, with its subspecies sputorum and bubulus. However, doubts have been expressed about the present scheme (Karmali et al., 1983) and a new species has recently been proposed (Gebhart et al., 1983). Campylobacters are important in human and veterinary medicine. $C$. jejuni causes enteritis in man and animals (Prescott and Munroe, 1982) and abortion in sheep. C. fetus is associated with abortion and other reproductive disorders in cattle and sheep (Smibert, 1978) and also occasionally with human infections (Righter et al., 1983). In New Zealand, C. fetus ss. fetus is an important cause of abortion in sheep (Gumbrell and Christiansen, 1982; Quinlivan and Jopp, 1982). Although the annual incidence of abortions associated with $C$. fetus ss. fetus varies, in every year some farms experience major outbreaks, sometimes affecting over one third of the animals in a flock. The reasons for the variation in annual incidence and for the sporadic occurrence of major outbreaks are not clear. Attempts to study the problem are hampered by the lack of an adequate typing system. Serological typing has been attempted, but only two broad serogroups could be confidently identified (Bird et al., 1984). 
Restriction endonuclease analysis, a technique used widely for comparing and typing viruses (Robinson, Ellis and Balassu, 1982; McIntosh and Ignoffo, 1983), has recently been applied successfully to the typing of bacteria (Marshall, Wilton and Robinson, 1981; Kaper et al., 1982). The technique consists of extraction of DNA from the organism, digestion of the DNA with a restriction endonuclease, and separation of the DNA fragments by agarose-gel electrophoresis. Restriction endonucleases recognise and cleave specific base-pair sequences and so digest a particular DNA strand into a unique set of fragments. Electrophoretic migration of the fragments produces a pattern of bands that may be used as a "fingerprint" to characterise the organism from which the DNA was extracted.

This study investigated the potential of restriction endonuclease analysis for distinguishing between different species of Campylobacter and for differentiating between strains of $C$. fetus ss. fetus.

\section{MATERIALS AND METHODS}

Bacteria. The reference strains of Campylobacter examined in this study are listed in the table. Wild strains of $C$. fetus ss. fetus were isolated from 43 sheep abortions occurring on 10 different farms over a period of 3 years. Strain C 30 was an isolate of C. fetus ss. venerealis from a local bovine-infertility study. The identity of strain $\mathrm{C} 30$ and of the wild $C$. fetus ss. fetus strains was confirmed by standard biochemical tests (Véron and Chatelain, 1973).

Preparation of DNA. Strains were cultured on Columbia Agar (Oxoid Ltd, Basingstoke, Hants) containing 7\% defibrinated sheep blood (Gibco, Penrose, Auckland, New Zealand) and Skirrow antibiotic supplement for C. fetus (Oxoid). Cultures were grown for 4-5 days at $37^{\circ} \mathrm{C}$ in a microaerophilic atmosphere produced by a gas generating kit (Oxoid) in an anaerobic jar without a catalyst. Approximately $0.2 \mathrm{~g}$ wet weight of cells was washed in $0.15 \mathrm{M}$

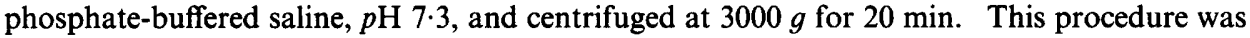
repeated twice to remove traces of culture medium. The final pellet was suspended in $1 \mathrm{ml}$ of buffer consisting of $100 \mathrm{~mm}$ ethylenediamine tetra-acetic acid disodium salt (EDTA) and $100 \mathrm{~mm}$ Tris- $\mathrm{HCl}, p \mathrm{H} \mathrm{8.5}$. DNA was extracted by the method of Marshall et al. (1981). This consists of treating the cells with lysozyme, lysing them with sodium dodecyl sulphate in the presence of non-specific proteases, and extracting DNA from the lysis mixture with phenol:chloroform: isoamyl alcohol (25:24:1); the DNA extract is then subjected to exhaustive dialysis. The concentration of DNA in each extract was measured by fluorimetry (le Pecq and Paoletti, 1966) after adding RNAase (Type X-A, Sigma Chemical Company, Saint Louis, MO 63178, USA). The purity of each extract was assessed by measuring the ratio of UV absorbance at $260 \mathrm{~nm}$ to that at $280 \mathrm{~nm}$.

Restriction endonuclease analysis. Campylobacter DNA $(0 \cdot 6 \mu \mathrm{g})$ was digested to completion with either of the two restriction enzymes Xho I or BstE II (New England Biolabs, Beverly, MA 01915 , USA) at the digestion temperature and with the buffer specified by the supplier. Gel electrophoresis was performed in horizontal slabs of $0.5 \%$ agarose (standard low $\mathrm{M}_{\mathrm{r}}$; Bio-Rad, Richmond, CA 94804, USA) immersed in a buffer consisting of $40 \mathrm{~mm}$ Tris-acetate, $5 \mathrm{~mm}$ sodium acetate, and $1 \mathrm{~mm}$ EDTA, $p \mathrm{H} 7 \cdot 8$. After electrophoresis at $1 \mathrm{~V} / \mathrm{cm}$ for $16 \mathrm{~h}$ the gels were stained for $30 \mathrm{~min}$ in ethidium bromide $0.5 \mu \mathrm{g} / \mathrm{ml}$. Stained gels were placed on an ultraviolet transilluminator (Ultraviolet Products, San Gabriel, CA 91778, USA) and the fragment patterns were photographed on Kodak Tri-X film by a 120 format plate camera with a Wratten $23 \mathrm{~A}$ gelatin filter.

\section{RESULTS}

The mean and standard deviation of the $260 \mathrm{~nm}$ to $280 \mathrm{~nm}$ absorbance ratios of the DNA extracts was $1 \cdot 94 \pm 0 \cdot 10$. The amount of DNA obtained from each extract was in the range $30-120 \mu \mathrm{g}$ in a total volume of $c .2 \mathrm{ml}$. 


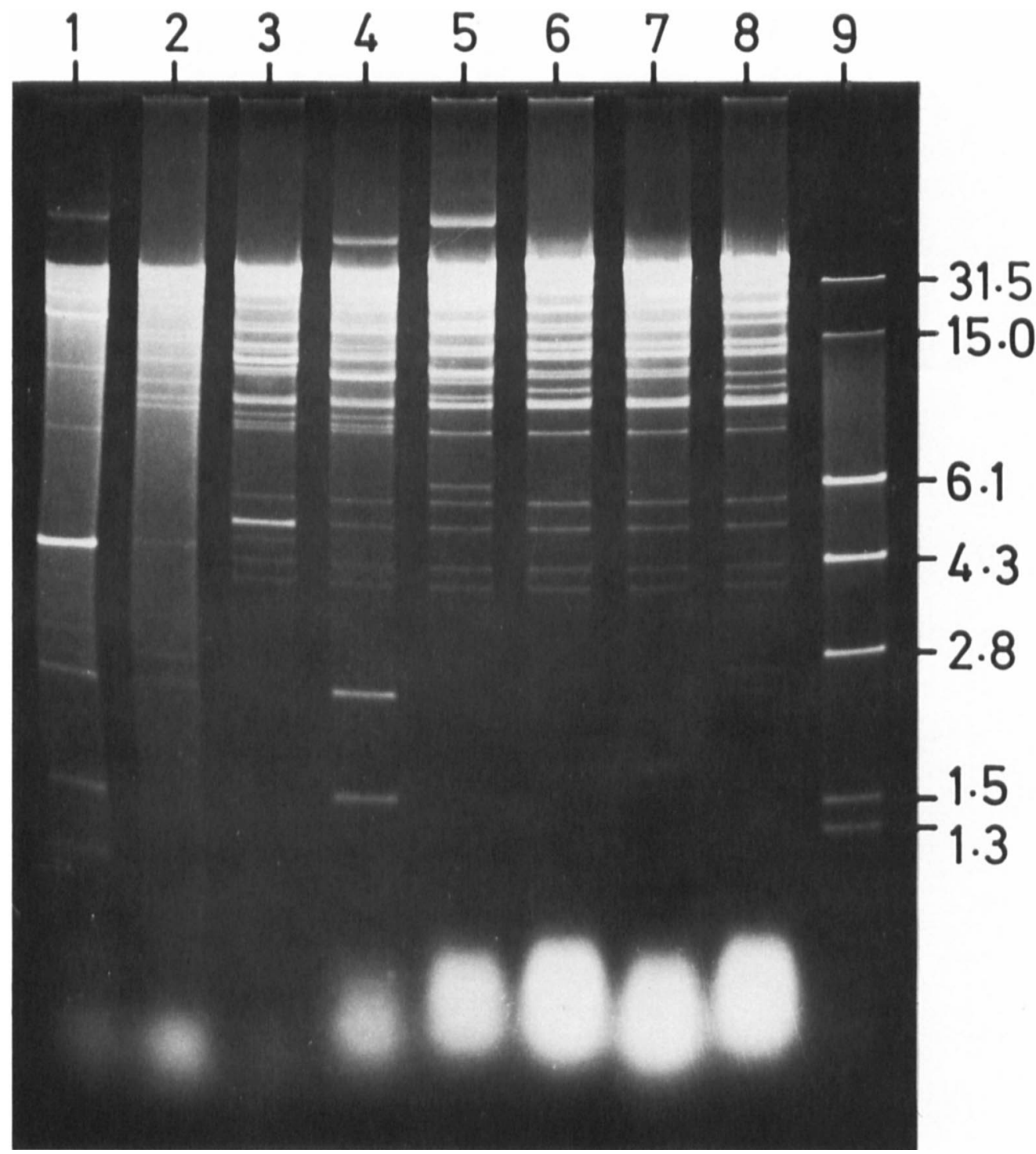

FIG. 1.-Fragment patterns after BstE II digestion of DNA from (1) C. coli (NHI2607), (2) C. jejuni (NHI2397), (3-5) C. fetus ss. venerealis (NHI2399, NHI1095, C30), (6-8) C. fetus ss. fetus (NHI2398, NHI 1084, NHI1214). Lane 9 contained uncut $\lambda$ phage plus a Hind III digest of $\lambda$ phage; the mol. wts of the fragments are indicated $\left(\times 10^{6}\right)$.

The results of agarose-gel electrophoresis of restriction endonuclease digests are shown in figs. 1,2 and 3. DNA extracts were always completely digested into discrete lines in the conditions used, and doubling the digestion time or the amount of restriction enzyme did not change any of the patterns. The diffuse spot at the low-mol.-wt end of each lane is due to the presence of RNA. To facilitate comparisons, strains whose patterns are most similar have been placed in adjacent 


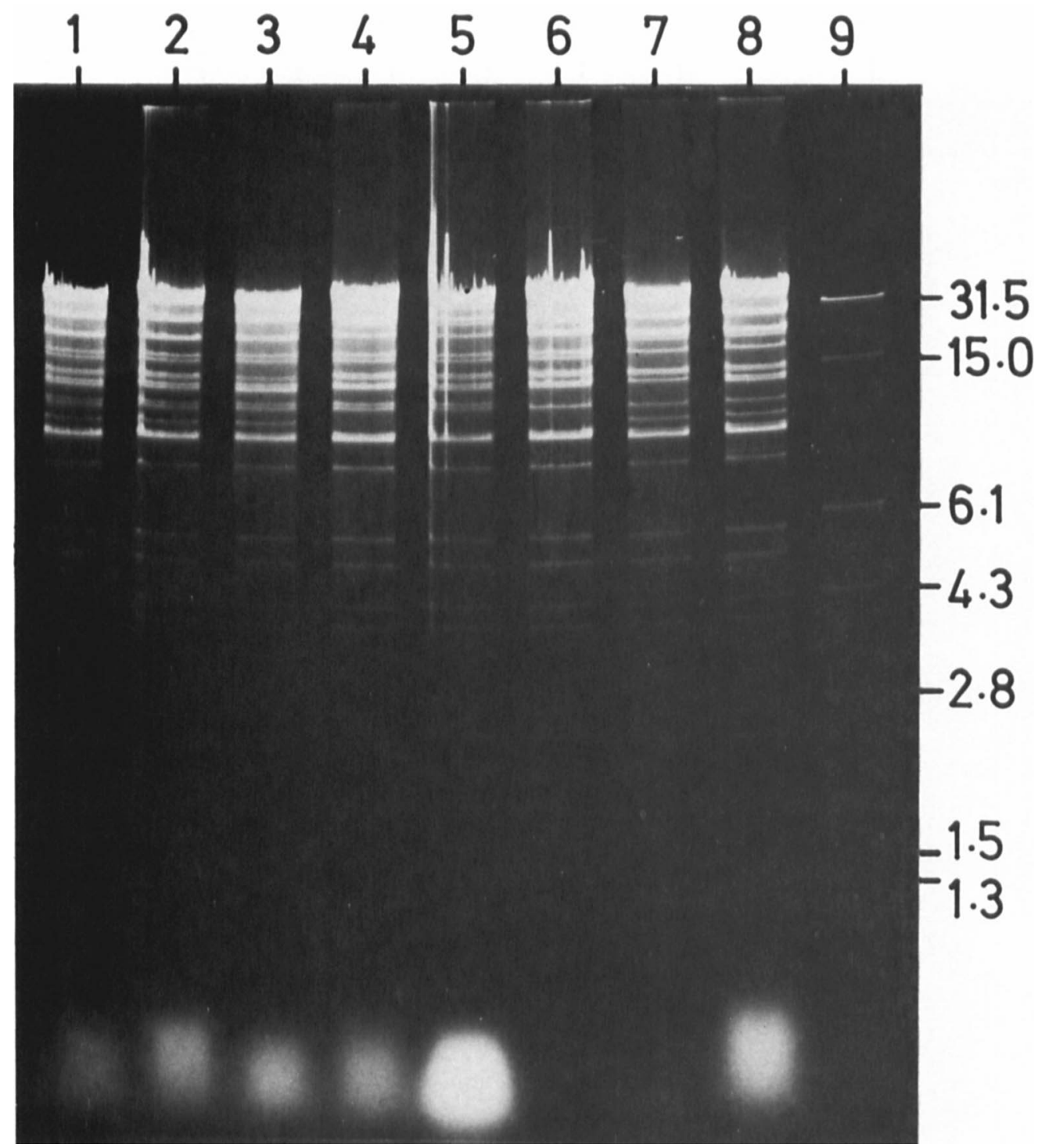

FIG. 2.-Fragment patterns after BstE II digestion of DNA from strains of $C$ fetus ss. fetus; local (New Zealand) strains are designated types A-D: (1) NHI2398, (2) NCTC5850, (3) type A strain, (4) NHI1084, (5) type D strain, (6) type B strain, (7) type C strain, (8) NHI1214. Lane 9 contained uncut $\lambda$ phage plus a Hind III digest of $\lambda$ phage; the mol. wts of the fragments are indicated $\left(\times 10^{6}\right)$.

lanes. Uncut $\lambda$ phage together with a Hind III digest of $\lambda$ phage have been placed in one lane of each gel to indicate the mol. wt of the campylobacter DNA fragments.

Fig. 1 shows a comparison of BstE II digests of DNA from reference strains of $C$. coli, $C$.jejuni, $C$. fetus ss. venerealis and $C$.fetus ss. fetus. The patterns produced by the $C$. coli and $C$. jejuni strains were strikingly different from each other and from those of the $C$. fetus strains. In contrast, nearly half of the DNA bands were shared by all strains of the two subspecies of $C$. fetus (ss. venerealis and ss. fetus). 


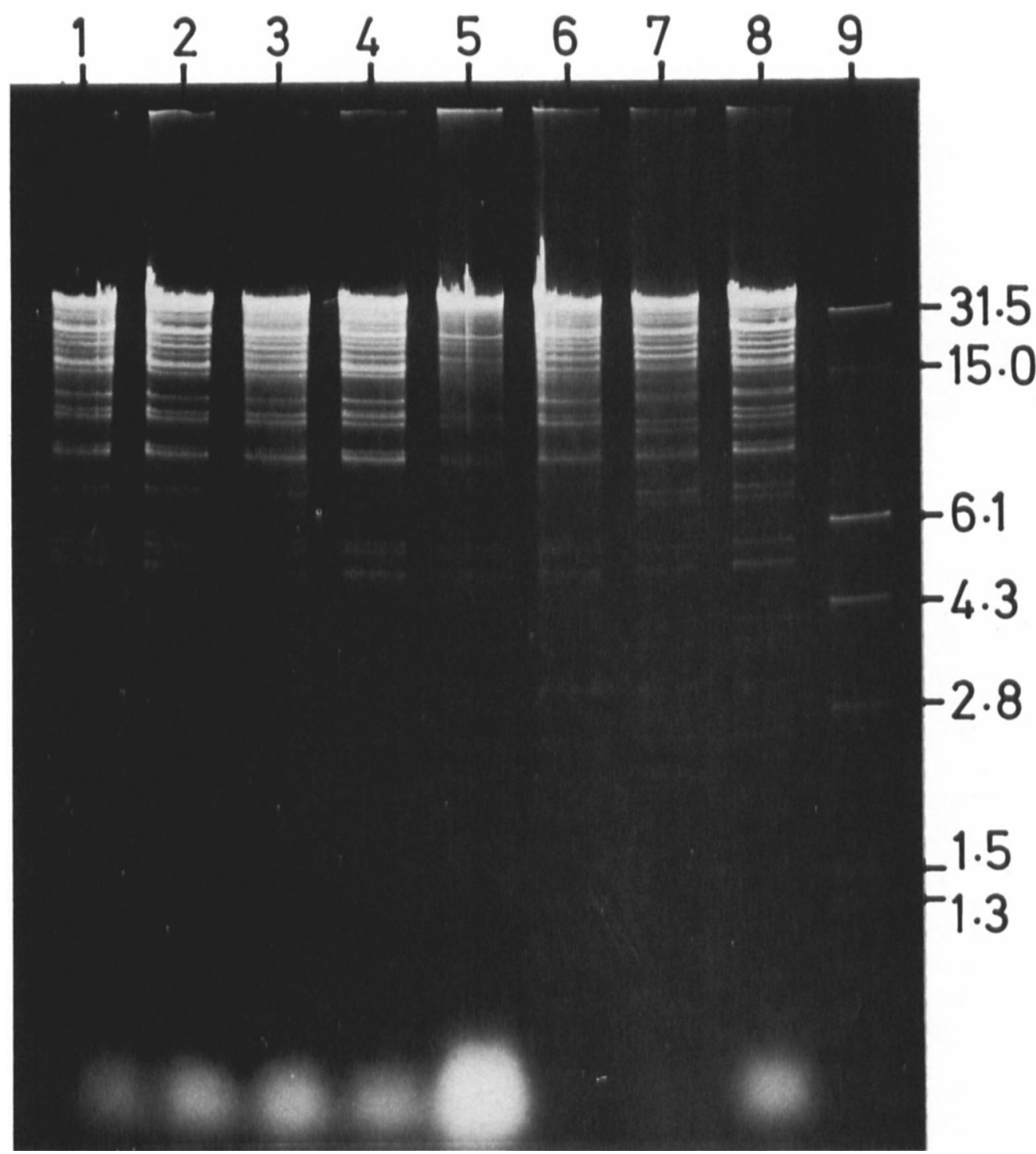

FIG. 3.-Fragment patterns after $X$ ho I digestion of DNA from strains of $C$. fetus ss. fetus; local strains are designated types A-D: (1) NHI2398, (2) NCTC5850, (3) type A strain, (4) NHI1084, (5) type D strain, (6) type B strain, (7) type C strain, (8) NHI1214. Lane 9 contained uncut $\lambda$ phage plus a Hind III digest of $\lambda$ phage; the mol. wts of the fragments are indicated $\left(\times 10^{6}\right)$.

Figs. 2 and 3 show BstE II and Xho I digests of DNA from reference and local strains of $C$. fetus ss. fetus. Four restriction patterns were distinguished in the local strains of $C$. fetus ss. fetus. These have been designated types A-D and are shown in lanes 3, 5, 6 and 7 (figs. 2 and 3). All 43 local strains gave patterns identical to one or other of these four types and those that gave a particular pattern with BstE II invariably produced a single pattern when digested with Xho I. There were 13 type-A strains, 24 type B, 5 type C, and 1 type D. No more than two different types were 
isolated from any farm. In the single instance in which the organism was isolated in each of three successive years from the same farm, all isolates were of the same type. The four patterns produced by BstE II DNA-digests from the local strains were easily distinguished from each other by the absence or the position of bands with mol. wts of $(10-11 \cdot 5) \times 10^{6}$ (fig. 2). In the Xho I digests the distinctive differences were in the regions immediately above and below the two common bands centred on a mol. wt of $10 \times 10^{6}$ (fig. 3).

DNA patterns from the reference strains NHI2398 and NCTC5850 appeared identical (lanes 1 and 2, figs. 2 and 3) and were also closely similar to the patterns produced by the type-A local strains, although a slight difference was evident in the thickness of the band of mol. wt $15 \times 10^{6}$ in the BstE II digests (lane 3, fig. 2). This slight difference was reproducible and was not an artefact. Reference strain NHI1084 produced a pattern nearly identical to that of the local type-D strain (lanes 4 and 5 , figs. 2 and 3$)$.

\section{Discussion}

The $260 \mathrm{~nm}$ to $280 \mathrm{~nm}$ absorption ratios of the DNA extracts indicated that the DNA in this study was substantially free of protein contamination. The DNA concentrations were measured fluorimetrically because experience showed this to be more reliable than basing them on the absorption at $260 \mathrm{~nm}$.

No difficulty was experienced in digesting these DNA extracts with the enzymes used. Digestion was invariably complete, though this is not apparent in the high mol.-wt regions of the illustrations because the films were given a generous exposure to reveal the low-mol.-wt fragments. After digestion with either of the two enzymes, the largest DNA fragments had mol. wts greater than that of $\lambda$ phage $\left(31 \cdot 5 \times 10^{6}\right)$. For such large fragments to be obtained it is important that the DNA has an even higher mol. wt before it is digested. Common techniques of DNA preparation such as ultrasonic disintegration, ethanol precipitation, spooling, and vigorous extraction were avoided as these generally cause extensive shearing of very high-mol.-wt DNA. No attempt was made to remove RNA from the extracts as it did not interfere with the technique.

The recognition of four Campylobacter spp., implicit in acceptance of the "approved names" (Skerman et al., 1980), is based on phenotypic tests and supported by studies of the guanine plus cytosine content of the DNA and of DNA homology (Véron and Chatelain, 1973; Owen and Leaper, 1981; Belland and Trust, 1982). C. fetus ss. fetus and $C$. fetus ss. venerealis are distinguished by their different biochemical and ecological characters (Véron and Chatelain, 1973). It is informative to compare the DNA-fragment patterns of the various strains analysed in this study in the light of this classification. The definite differences in pattern produced by $B s t \mathrm{E}$ II digestion of DNA from the separate species $C$. coli, $C$. jejuni and $C$. fetus and the many regions of similarity in the patterns produced by all strains of the two subspecies $C$. fetus ss. fetus and $C$. fetus ss. venerealis agree well with the current classification system, although it must be admitted that $C$. jejuni and $C$. coli were represented by only one strain each (table). Digestion by the restriction enzyme Xho I (gel not shown) produced similar results. Restriction endonuclease analysis clearly has a useful role to play in classification of the genus Campylobacter. 
TABLE

Reference strains of Campylobacter used in this study*

\begin{tabular}{lll}
\hline \multicolumn{1}{c}{ Organism } & Strain number & \multicolumn{1}{c}{ Synonymous designation } \\
\hline C. fetus ss. fetus & NHI1214 & \\
& NHI1084 & CDCD1278 \\
& NHI2398 & NCTC10842, ATCC27374, CIP5396 \\
NCTC5850 & \\
C. fetus ss. venerealis & NHI1095 & \\
C. Nejuni & NHI2399 & NCTC10354, ATCC19438, CIP6829 \\
C. coli & NHI2607 & NCTC11351, CIP702 \\
\end{tabular}

* Abbreviations: NHI, National Health Institute, Wellington, New Zealand; NCTC, National Collection of Type Cultures, London, England; ATCC, American Type Culture Collection, MD, USA; CDC, Centers for Disease Control, Atlanta, GA, USA; CIP, Collection of the Institute Pasteur, Paris, France.

It is difficult to compare quantitatively the results obtained by restriction endonuclease analysis with those obtained by DNA homology studies, because the two approaches are so different. However, it is interesting to note that although a number of differences are apparent between the patterns produced by the two reference strains C. fetus ss. venerealis NHI2399 and C. fetus ss. fetus NHI2398 (lanes 3 and 6, fig. 1), these two strains could not be distinguished by DNA homology under stringent conditions (Belland and Trust, 1982). Restriction endonuclease analysis thus appears to be a more sensitive technique than DNA homology for detecting differences in the genome of C. fetus strains. However, it is not possible on the basis of this present work to assess the biological significance of these differences.

Restriction endonuclease analysis revealed four different types of $C$. fetus ss. fetus. It also showed that reference strains isolated many years ago in other countries were very similar to two of the types associated with sheep abortion in New Zealand. The finding of a single restriction type in isolates obtained from one farm in three successive years indicated the stability of the restriction patterns through many generations. Typing by restriction endonuclease analysis is currently being used to investigate and improve serological typing systems of $C$. fetus ss. fetus and to study the epidemiology of sheep abortion in New Zealand.

The authors gratefully acknowledge the assistance of Dr G.W. de Lisle for supplying the strains of Campylobacter used in this study and for his helpful comments.

\section{REFERENCES}

Belland R J, Trust T J 1982 Deoxyribonucleic acid sequence relatedness between thermophilic members of the genus Campylobacter. Journal of General Microbiology 128:2515-2522.

Bird M M E, Stephens D J, Wall E P, De Lisle G W 1984 Serology of Campylobacter fetus fetus strains from four outbreaks of ovine abortion. New Zealand Veterinary Journal 32:14-17.

Gebhart C J, Ward G E, Chang K, Kurtz H J 1983 Campylobacter hyointestinalis (new species) isolated from swine with lesions of proliferative ileitis. American Journal of Veterinary Research 44:361-367.

Gumbrell R C, Christiansen K H 1982 Sheep abortion in New Zealand. New Zealand Veterinary Journal Conference Supplement 30:vi, vii. 
Kaper J B, Bradford H B, Roberts N C, Falkow S 1982 Molecular epidemiology of Vibrio cholerae in the U.S. Gulf Coast. Journal of Clinical Microbiology 16:129-134.

Karmali M A, Penner J L, Fleming P C, Williams A, Hennessy J N 1983 The serotype and biotype distribution of clinical isolates of Campylobacter jejuni and Campylobacter coli over a three year period. Journal of Infectious Diseases 147:243-246.

Le Pecq J, Paoletti C 1966 A new fluorometric method for RNA and DNA determination. Analytical Biochemistry 17:100-107.

McIntosh A H, Ignoffo C M 1983 Restriction endonuclease patterns of three baculoviruses isolated from species of Heliothis. Journal of Invertebrate Pathology 41:27-32.

Marshall R B, Wilton B E, Robinson A J 1981 Identification of leptospira serovars by restriction endonuclease analysis. Journal of Medical Microbiology 14:163-166.

Owen R J, Leaper S 1981 Base composition, size and nucleotide sequence similarities of genome deoxyribonucleic acids from species of the genus Campylobacter. FEMS Microbiology Letters 12:395-400.

Prescott J F, Munroe D L 1982 Campylobacter jejuni enteritis in man and domestic animals. Journal of the American Veterinary Medical Association 181:1524-1530.

Quinlivan T D, Jopp A J 1982 A survey on the incidence and cause of ovine abortion in Hawkes Bay. New Zealand Veterinary Journal 30:65-68.

Righter J, Wells W A, Hart G D., McNeely D J 1983 Relapsing septicemia caused by Campylobacter fetus subsp. fetus Canadian Medical Association Journal 128:686-689.

Robinson A J, Ellis G, Balassu T 1982 The genome of orf virus: restriction endonuclease analysis of viral DNA isolated from lesions of orf in sheep. Archives of Virology 71:43-55.

Skerman V B D, McGowan V, Sneath P H A 1980 Approved lists of bacterial names. International Journal of Systematic Bacteriology 30:225-420.

Smibert R M 1978 The genus Campylobacter. Annual Review of Microbiology 32:673-709.

Véron M, Chatelain R 1973 Taxonomic study of the genus Campylobacter Sebald and Véron and designation of the neotype strain for the type species Campylobacter fetus (Smith and Taylor) Sebald and Véron. International Journal of Systematic Bacteriology 23:122-134. 